\title{
Non Hodgkin's Lymphoma Presenting with Urticarial Vasculitis - A Rare Association
}

\author{
N PURI ${ }^{\mathrm{a}}$, SK MALHOTRA ${ }^{\mathrm{b}}$
}

\begin{abstract}
Summary:
Urticarial vasculitis (UV) has been described as a rare association with hematological malignancy. We report the case of a 52 year old patients of localized B-cell nonHodgkin's lymphoma who presented with a recurrent nonpainful urticarial type rash distributed around his face, arms, forearms, buttocks and lower legs since 1 year. The patient was managed by intensive combination
\end{abstract}

\section{Introduction:}

Urticarial vasculitis (UV) has been described as a rare association with hematological and visceral malignancy. It is thought that tumour aassociated immune complexes might be involved in the pathogenesis of the vasculitis. Non-Hodgkin's lymphomas (NHLs) arise from the malignant, monoclonal transformation of lymphocytes. As a disease group they encompass a hodgepodge of histological types, cell lines and tumour grades. About $85 \%$ of NHLs derive from $\mathrm{B}$ cells, the rest from $\mathrm{T}$ cells. Low-grade disease predominantly occurs in elderly patients, with indolent courses and median survival times of 5-8 years. High-grade disease accounts for less than $5 \%$ of all NHLs and typically presents as rapidly progressive cancer in children and young adults. Intermediate-grade disease is the most common type, accounting for $65 \%$ of all NHLs and affecting any age group. ${ }^{1}$

Increased exposure to sunlight, with its resulting immunosuppressive effect, may be one of the factors for rise in incidence of Non Hodgkin's lymphoma. ${ }^{2}$ Immunosuppression plays a role in the cause of some

a. Dr. Neerja Puri, MD, Registrar Dermatology

b. Dr. SK Malhotra, MD, Associate Prof \& Head

Department Of Dermatology, Leprosy \& Venereology, G.G.S. Medical College \& Hospital, Faridkot. 151203. Punjab.

Address of Correspondence: Dr Neerja Puri, \# 626, Phase II, Urban Estate, Dugri Road, Ludhiana, Punjab. India, Email : neerjaashu@rediffmail.com Cell :09814616427

Received: 25 December, 2008

Accepted: 7 September, 2009 chemotherapy (CHOP) regime for several cycles. The patient showed good response to treatment. The case is being reported because of the rare association of Non Hodgkin's lymphoma with urticarial vasculitis.

Key Words : Lymphoma; lymphadenopathy; chemotherapy; bone marrow; lymphoid; cutaneous; histology.

(J Bangladesh Coll Phys Surg 2011; 29: 41-43)

lymphomas. Transplant recipients are 35 times more likely than the general population to acquire NHL and the disease is a common manifestation of AIDS.

Numerous cutaneous manifestations can be associated with malignancies. About $50 \%$ of patients with lymphomas have cutaneous manifestations at some time during the course of disease. Epstein and MacEachenill divided cutaneous manifestations of lymphomas into specific malignant infiltrates and non-specific manifestations. ${ }^{3}$ Specific malignant infiltrates are the ones which show characteristic malignant cells on histopathological examination. Non-specific lesions associated with lymphomas c be classified into infections, non-infective conditions and changes due to chemotherapy. ${ }^{4}$ urticarial vasculitis is a cutaneous manifestation of visceral and haematological malignancy and is considered to be rare. ${ }^{5}$

\section{Case Report}

A 52-yr-old male presented with a 6 years of generalized arthralgia, myalgia and weight loss. On examination, he had a recurrent non-painful urticarial-type rash distributed around his face(Fig 1), arms, forearms, buttocks and lower legs since 1 year. The lesions persisted for 2-3 days and then subsided with residual pigmentation. The skin lesions developed three years after treatment of NHL. One month after the rash there was bilateral wrist and metacarpophalangeal joint synovitis. On systemic examination, the patient had right cervical, supraclavicular and bilateral inguinal lymphadenopathy . 
Investigations revealed an erythrocyte sedimentation rate (ESR) of $109 \mathrm{~mm} / \mathrm{h}, \mathrm{C}$-reactive protein (CRP) concentration $157 \mathrm{mg} / \mathrm{l}$, complement component C3 $2.24 \mathrm{~g} / \mathrm{l}$ (normal range $0.7-1.7 \mathrm{~g} / \mathrm{l}$ ) and C4 $0.57 \mathrm{~g} / \mathrm{l}$ (normal range $0.13-0.43 \mathrm{~g} / \mathrm{l}$ ). Screening for rheumatoid factor and autoantibody was negative. The peripheral blood film showed normocytic, normochromic RBC's showing little anisocytosis and poikilocytosis with eosinophilia. The platelet count of the patient was 1,80,000/cu mm and PTI (Prothrombin time index) was $80 \%$. Lymph node biopsy showed an occasional lymphoid follicle with scanty mantle. The biopsy showed nodular architecture with replacement of parent tissue by sheets of small lymphoid cells having coarse chromatin scanty cytoplasm, cleaved nucleus with prominent indentations and infoldings. The cells were present diffusely in nodules. The medullary siniuses were congested and cords contained few plasma cells. The diagnosis of non hodgkins lymphoma (Monocytoid B cell type) was made. Bone marrow aspiration showed cellular marrow with normoblastic maturation with megaloblastic change. The megakaryocytes were normal in number and morphology. The marrow showed increased number of lymphoid and lymphoplasmacytoid cells constituting $20 \%$ of all nucleated cells. The myeloid:erythroid ratio was 1.6:1.

The ultrasound abdomen showed evidence of multiple enlarged hypoechoic abdominal lymph nodes seen involving paraortic, portocaval and coleliac axis groups with spleenomegaly. There was no free fluid in the abdomen. There was ultrasonographic evidence of cholelithiasis with splenomegaly with lymphadenopathy.

The skin biopsy showed following findings :- Epidermis was normal. Moderately dense mixed cellular infiltrate of lymphocytes, eosinophils and neutrophils was present in the papillary and upper dermis as well in betwen the dermal collagen fibres. Fibrinoid necrosis of vessel was absent but extravascated erythrocytes was noted (Fig 2). There was prominence of the endothelial cells lining the blood vessels with a chronic lymphocytic infiltrate around the dermal blood vessels. The pathology was consistent with urticarial vasculitis. A diagnosis of urticarial vasculitis was made and the patient was commenced on prednisolone $20 \mathrm{mg}$ daily for recurring skin lesions and persistent synovitis. Two weeks later, there was a clear response to treatment, with resolution of the rash (with residual pigmentation) and no synovitis.
ESR and CRP had also fallen and complement levels had normalized. His symptoms returned on reduction of the prednisolone dose, and methotrexate $10 \mathrm{mg}$ weekly was commenced as a steroid-sparing agent. The patient was later put on intensive combination chemotherapy (CHOP) regime for several cycles. The patient showed good response to treatment.

\section{Discussion:}

People with NHL may be asymptomatic or may present with a range of features (e.g. painless lymphadenopathy, abdominal mass, weight loss or night sweats) or with symptoms specific to the tumour bulk in the involved sites, such as the tonsils, abdomen, thyroid or lung. 6,7 All patients require careful staging, which involves a thorough physical examination, CT scanning and bone marrow biopsy. Management is complex and requires referral to a cancer treatment centre. Patients with indolent lymphomas may undergo watchful waiting at first, but eventually they will require treatment with an alkylating agent such as chlorambucil, with or without steroid therapy. ${ }^{8}$ The standard chemotherapy for intermediate-grade NHL is several cycles of CHOP (cyclophosphamide, doxirubicin, vincristine and prednisolone), administered intravenously and sometimes supplemented by radiotherapy. ${ }^{9}$ Treatment of high-grade NHL is urgent, usually requiring intensive combination chemotherapy. Prognosis and response to therapy depends on the age of the patient and the tumour stage and subtype. Although UV is known to be associated with other connective tissue diseases, its association with malignancy is less well established. A review of the literature revealed five definite cases of UV associated with malignancy. ${ }^{10}$ Two patients who had received therapy for Hodgkin's disease presented with UV. One case of UV associated with immunoglobulin A myeloma has been described ${ }^{11}$ and two further cases have occurred in association with both metastatic adenocarcinoma of the colon ${ }^{12}$ and metastatic malignant teratoma of the testes. ${ }^{13}$

To describe UV as a paraneoplastic phenomenon highlights the importance of excluding malignancy as an underlying cause. ${ }^{14}$ While the histological appearances were not typical of a florid leucocytoclastic vasculitis in this case, in new-onset UV there may be little vessel wall disruption and only a minor degree of perivascular infiltration. ${ }^{15}$ The exact pathogenesis of the 
association with malignancy is unclear, but in malignancy immune defects occur which may give rise to complement fixation in vessel walls and subsequent development of a vasculitis.

\section{References:}

1. Burg G, Dummer R, Kerl H. Classification of cutaneous lymphomas. Dermatol Clin 1994 Apr. 209-210.

2. Mackie RM. Cutaneous lymphomas and lymphocytic infiltrates, In: Rook, Wilkinson, Ebling. Textbook of Dermatology, Edited by, Champion RH, Burton TL, Bums DA, et aI, Blackwell Science, Oxford, 1998:2379-2381.

3. Epstein E, MacEachern K. Dermatological manifestations of the lymphoblastoma-leukemia group. Arch Intern Med 1937:60:867.

4. Piette WW Leukemia and lymhomas, In: Dermatological signs of Internal Disease, Edited by Callen JP, Jorizzo J, Greer KE, et al, WB Saunders Co, Philadelphia, 1988;118-121.

5. Wilson D, McCluggage WG, Wright GD. Urticarial vasculitis : a paraneoplastic presentation of B cell non Hodgkin's lymphoma. Rheumatology 2002 Apr; 41(4) : 476-477.

6. Isaacson PG, Norton AJ. Extra-nodal lymphomas. Churchill Livingstone: Edinburgh; 1994. p. 1

7. Anagnostopouler D, Pangalis GA, Kittas C. Extra-nodal Lymphoma: A review. Haema 2001;4:215-9.
8. Salama S. Primary cutaneous B cell lymphoma and lymphoproliferative disorder of skin: Current status of pathology and classification. Am J Clin Pathol 2000;114:S104-28.

9. Freedman AS, Nodler LM. Malignant lymphomas, In:Harrisor s Principles of Internal Medicine, Edited by lesselbacher KJ, Braunwald E, Wilson JD, et aI, McGraw-Hill Inc, New York, 1994; 1977-1988.

10. Strickland D, Ware R. Urticarial vasculitis: an autoimmune disorder following therapy for Hodgkin's disease. Med Paediat Oncol1995;25:208-12.

11. Highet A. Urticarial vasculitis and IgA myeloma. Br J Dermatol 1980;102:355-7.

12. Lewis JE. Urticarial vasculitis occurring in association with visceral malignancy. Acta Dermatol Venereol1990;70:3457.

13. Sprossmann A, Muller RP. Urticarial vasculitis syndrome in metastatic malignant testicular teratoma. Hautarzt1994;45:871-4.

14. Garcia-Porrua C, Gonzalez M. Cutaneous vasculitis as a paraneoplastic syndrome in adults. Arthritis Rheum1998;41:1133-6.

15. Elder D et al. Lever's Histopathology of the skin. 8th ed. Lippincott, Raven: Philadelphia, NY; 1997. p 808. 